\section{INDICES CONVERTING RESIGNATION AND DROP-OFFS OF BUSINESS STUDENTS TO RETENTION}

\begin{abstract}
Each new generation brings a challenge to employers, university management and teachers with new attitudes affecting their continuous matriculation and degree completion. This article discusses how to retain both business and institutional career-oriented students using real-time communication based on their attitudes, emotions resulting from logically generated synonyms by automatic data evaluation by the information system. The objective of this article is to identify these students early in their academic studies and to assess their likelihood for continuous matriculation and ultimately increase retention rates. Using data from entry questionnaire during application at university, based on their attitudinal expectation, students were categorised into groups that affected their continuous matriculation. Data used in this study were gathered by compulsory entry questionnaire of 535 students in the academic year 2017-2018. Using statistical and dimensional analysis, four groups were identified among university applicants: Proactive, Reactive, Lazy and Institutional. Responses were tested according to Complementary Distribution Function (CDF) and normal distribution as Probabilistic Distribution Function (PDF). Antagonist attitudes were found for answers corresponding to PDF and CDF. Results indicate that business and institutionally oriented students should be separated and treated individually to increase retention.
\end{abstract}

\section{KEYWORDS}

\section{Attitudes, behaviour, persistence, retention, student, university}

\section{HOW TO CITE}

Vnoučková L., Linhart Z. (2020) 'Indices Converting Resignation and Drop-Offs of Business Students to Retention', Journal on Efficiency and Responsibility in Education and Science, vol. 13, no. 2, pp. 79-89. http://dx.doi.org/10.7160/eriesj.2020.130203

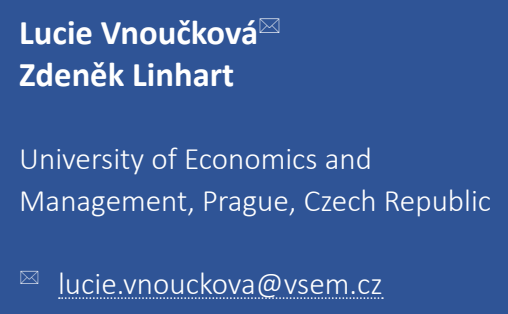

Lucie Vnoučková

Article history

Received

June 17, 2019

Received in revised form

September 27, 2019

Accepted

March 13, 2020

Available on-line

June 30, 2020

\title{
Highlights
}

- Four groups of students were identified: Proactive, Reactive, Lazy and Institutional.

- Evaluation of entry questionnaires based on synonyms can be used as predictors of student retention.

- The progress in data evaluation and quality management of university recruitment by systematic analyses is shown at case business university.

- The result of this study is that student behaviour measured by synonyms allow projection of their desired preferences that can be used to create retention strategies.

\section{INTRODUCTION}

According to Thatcher et al (2016), Deveci (2015), and others, student's preferences at both private and public universities play a vital role to keep up the pace with the competition. Student's preferences show imaginary characteristics of the educational process in order to keep students satisfied. These preferences or perceived values are important to realize that the student's satisfaction with the organization of education, professional prospects, staffing, etc. affects the further formation of a college or university for potential new students (Kim et al, 2014; Aregbeyen, 2010). The opinion and feedback given by potential students have become one of the most important determinants of management and educational processes in higher education (Esparza et al, 2018). Collins et al (2017) in their research identified the benefits of undergraduate research participation for university students. The positive outcomes of participation are a robust positive predictor of five factors: gains in knowledge and skills, institutional support, overall satisfaction, grade point average, and student-faculty interaction.

There are several variables explaining the demand for higher education, which include e.g. individual, social, economic, and other factors (Duong, Wu and Hoang, 2017, Menon et al, 2017, Fürstenberg et al, 2017, Agbola and Cheng, 2017). For 
students, economic factors are broadly discussed as they drive their future social status and position. According to Menon et al (2017) and Guerin et al (2017), there is a significant link between the perceived rates of return and the intention of a student to start and finish tertiary education.

According to Staiculescu and Dobrea (2017), universities should consider students by the categories of development of cognitive, social and affective attributes, where students significantly benefit from complex psycho-pedagogy support, counselling, internships, and practice. Kember et al (2017) identified that subject-independent learning activities were the most effective mechanism for students, followed by exposure to a rich campus environment. Thus, the curriculum should be viewed holistically, because employability of graduates is a major concern of universities, organisations and domestic policy (Staiculescu and Dobrea, 2017). Accordingly, support of education reform should ensure professionalization of graduates, the development of skills and knowledge as well as soft-skills and competences with focus on enhancing the potential of students upon graduation. In this context, universities have to offer to their students not only educational services but also counselling, support and orientation services that address and develop students' potential for educational and career path. Changes of behaviour between generations of baby boomers, generation $\mathrm{Y}$, generation $\mathrm{Z}$ or any other name describing specific behaviour of different age groups are pushing especially private schools to adopt and change curricula to retain students.

The objective of this article is to identify these applicants based on their attitudes expressed in entry questionnaire, administered during application at university and to design and implement retention strategies specific to their unique attitude towards education. This early identification and classification of these indices will allow for specific and targeted retention strategies.

This paper is organized by sections, which includes introduction, theoretical background, methods, results, discussion, and conclusions. The methodology offers information on a research framework, sample size, measures and procedures. Results present intergroup behaviour and intragroup attitudes. Discussion links other results found in scientific papers and compare them or add to our results. The conclusion presents the study limitations and found attributes for managerial implications and theoretical contribution.

\section{Theoretical Background}

Retention is absorbing and continuing to keep students who are accepted for studies. The outcome of effective retention strategies is continuous matriculation, graduation and ultimately the attainment of educational and professional goals. Resignation, or drop-off, is describing oppose process when students are leaving studies... Verbal constructs describing resignation were defined by Zhang, Cao and Wang (2018). These authors identified that emotional intelligence (EI) with performance contribution satisfaction (PCS), efficiency satisfaction (ES), and interest satisfaction (IS) are main verbal constructs explaining the role of emotions in any process, behaviour and decision affecting resignation. These attributes are applied into the admission procedure and the behaviour of students during this process. Based on the results of Zhang, Cao and Wang (2018), EI and relationship satisfaction (RS) mediation role is only partial. Furthermore, this mediation role of passive-transactional leadership in the relationships of EI with RS and IS were identified but its mediating effects between PCS and ES were not found (Zhang, Cao and Wang, 2018). Emotions are mediating information transfer across all constructs except for the disconnected constructs of performance and efficiency satisfaction. Answers for PCS and ES were selected by respondents to show potential positive answers to balance the disconnected parts of verbalizing standard.

Further research tested or standardized disconnected synonyms of both PCS and ES. Yu et al (2016) iterate synonyms in vector space during the discriminative training of ambiguous cases. It is also possible to find that normativity replaces emotions and provoke observers to focus on the procedures of normative contestation, rather than on the substantive content of normative preferences (Sayer, 2011). Contents of normative contestation had a greater recovery of innovative liberal leaders during creation of norms with substantive content by purity/ sanctity, social conformity and respect for authority principles (Graham, Haidt and Nosek, 2009) favored by recent position holders. Stevens and Zampini (2018) noted that normative beliefs are congruent with upholding the legitimacy and reproducing favored positions of social groups who have the power to define who is conforming and who holds authority.

Both standardization and testing of experiments are the responsibility of organizations and does not help individual to deal with emotions and chronic thinking. Therefore, framing can construct active and dynamic message delivering particular interpretation to its recipients (Benford and Snow, 2000). User generated content is an example of such individual interpretation while firm generated content generates larger positive relationships with regard to durables and non-durables, and with consideration, purchase intent, and satisfaction for services (Colicev, Kumar, and O'Connor, 2019) as one of the constructs. Dylman and Barry (2018) found other constructs using performance differences of cognitive training.

Preventive, experiential, and agreeable style of marking responses can explain alternative attitudes, which originate in ambition to claim up in or drop-off from hierarchical organizations. Preference analysis and segmentation decision (Liu et al, 2019), willingness to admit wrongness (Fetterman et al, 2019), willingness to accept or willingness to pay (LloydSmith and Adamowicz, 2018, Luu, Ngo and Cadeaux 2018) explain retaining and repelling consequences of cognition arguing by dyadic perceptions of relationship value towards investments and performance. Boronczyk and Breuer (2019) were curious what changes the attitude more when rationalizing campaigns and maximizing benefits for its sponsors. Preexposure attitudes were similarly weak but significant. It was found that pre-exposure attitudes towards event are transferred to post exposure event reliably but without being associated with sponsor. Therefore, sponsors have no return on their support. Similarly, preventive sponsoring behaviour of teacher and parent have no impact on what happens in school. Reifkind 
(2018) have associated low loyalty to focal sponsors with generalized complaint of employers that job applicants ignore scheduled interviews and new hires never shows up.

Then, marketing communication processes, which create, communicate, deliver, and exchange offerings to customers, clients, partners, and society are needed to establish positive relationships and expected behaviour (AMA, 2013). These relationships are observable using demand deriving markers of core concept as needs, wants and money available (Kotler, 1991). Recent authors begin to derive demand from wants (Asma, 2017), which brings specific reactions according to will (Libet, 1985). Individuals with long term will are pushed into risk eventually loss oppose to individuals with short term (Tversky and Kahneman, 1983). Some authors (Wang et al., 2013, Aghakhani and Main, 2019) try to avoid this confusion of constructs by indeterminacy, which presents all these observations as useless due to apparent necessity to tolerate incomplete behaviour of individuals and groups who are preparing themselves for challenges. Industrial clusters last until tolerance of incomplete behaviour allows them to maintain over time the competitive advantages arisen from external economies and joint actions developed in the cluster itself (Pezoa-Fuentes and Vidal-Suñé, 2017). Internal shaping of attitudes towards expectations, stress, eventually, burnout from repayment of investments, makes willingness to admit wrongness operable. Therefore, we must expect that technical component of empathic utterances predicts client language (Fischer and Moyers, 2014). Technical aspects can be related to standards to novel direction for translating relational skills. We have to expect that specific provider statements must respect proportion of reflections of change talk in association with client change language and treatment of outcomes (Barnett et al, 2014).

Magill et al $(2016,2018)$ support the technical component as an active ingredient of motivational interviewing (MI) predicting treatment outcomes from proportion of change talk to sustain talk. Villarosa-Hurlocker et al (2019) predict proportion of change talk from relational skills of client MI in-session language (empathy, acceptance, collaboration, and autonomy support) with expectation that provider will evoke client change talk and soften sustain talk. Therefore, empathy served by technical component predicts and influence attitudes and target market decisions.

This research of different impact of attitudes on behaviour is often processed statistically. Roggers (1983) has assigned names to representatives of intervals according to their attitude towards innovation as innovators $(2.5 \%)$, adopters $(13.5 \%)$, early majority (34\%), late majority (34\%) and laggards (16\%). Many authors have extended this research framework of roles by general attitudes (Muehling, 1987) and its impact on parts of statistical distributions (Taleb, 2013, Bass, 1969) eventually its specific curves (Fenn, 2007, Kahneman, 2012, Schumpeter, 1926).

Phenomena of appearance in fat tails of normal distribution cause vulnerability. Therefore, Proactive, Reactive, Institutional and Lazy respondents in tails of normal distribution either offer complementary alternative or accumulate to preferred mainstream. The proactive respondents generate answers on questions in the first part, which list primary expected outcomes of studies (e.g. development of knowledge and skills). Reactive respondents, on the contrary, react on secondary outcomes of university education (e.g. ability development, gaining experience, broadening overview). Lazy respondents are responding to only one answer containing summary of all mentioned. Institutional respondents are only concerned about skills needed for their job position. The rest of the respondents belong to the group characterized by normal distribution. Complementary alternatives are usually more innovative and riskier than cumulated uniform behaviour. Probabilistic Distribution Function (PDF) characterize attitude of observer who is not able to distinguish who cumulate resources and who complement alternatives. In this study, we try to explain chasm between those who cumulate and those who complement by observation of internally used synonyms between respondents (Maloney, 2010). Cumulating and complementing respondents were analysed when the conjoint attributes form newness (high vs low) and functional newness (high vs low), resulting in a 2 $\times 2$ design. A total of 170 college students ( $58.2 \%$ female), age 18 to 35 , participated in the online survey for course credit. Respondents were shown a random set of products varying by form and functional information on the computer screen. After reviewing the product information, respondents were asked to make an adoption (Lee, Ho and $\mathrm{Wu}, 2018$ ). A positive attitude does not necessarily results into adoption when consumers make their final choice oppose to moderating role of consumer need for uniqueness. Passion for uniqueness allows early fit of both cumulating and complementing respondents across the chasm. Based on the above mentioned, hypotheses for this study are as follows:

H0: Probability distribution function hide trial and error marking synonyms in answers between many normal respondents while improving robustness of conversion of resignation to retention.

H1: Conformance of cumulative proactive and complementary reactive respondents is converting resignation into retention oppose to institutional and lazy respondents.

Marking synonyms in answers according to normal distribution demonstrates a will of respondents to be transparent in verification of all offers including of unverifiable ones. This consistency of reactions is essential investment developing the trust of collaborators. Lazy and intelligent respondent finds time to focus by skipping the longest list of answers. Once benefits prove to be idle, the feedback between Lazy and nonlazy respondents show, which synonyms of offers benefit their development. Non-lazy respondents observe and follow Lazy respondents. Therefore:

H1a: Impatience of lazy/intelligent respondents has neither positive nor negative impact on resignation and retention. Fear of lost post is demonstrated by neglecting of synonyms as precursor of drop-off according to prospect theory (Kahneman, 2012). Attitude and posts will retain if respect to institution is higher than own benefit by respondents who are waiting for call to action.

H1b: Institutionalists are making conversion of resignation to retention unmanageable.

Redundancy of synonyms is denied by standardized vocabulary, 
which ignores all future aspirations. This is demonstrated by answer 'all above'.

\section{METHODS}

The data used in this study came from a primary quantitative survey by means of the questionnaire investigation collected by web survey (CAWI method). The survey took place in 2017 at a case university, during the academic year 2017-2018. The sample size comprised of 535 students. The data file comprised two groups: (1) students who dropped off during the first month (240 respondents) and (2) students who successfully continued their studies during the first year, 295 respondents. Answers of both retained and drop off groups, were analyzed to identify differences between the two groups and for the possibility to predict their behaviour and to guide actions to retain more students within the first year.

The evaluated areas in the questionnaire and in the evaluation of data are separated on preference in study, benefits of study, and expected curriculum (Table 1). Questions used in the survey are linked to theories (see the theoretical background) and similar research studies. Respondents' reactions to target statements and their attitudes to the given matter were restricted by offering a set of several statements. The statements design is based on literature review and in some cases modified according to the specifics of the university to fit its conditions. This study focuses on a more indepth discussion of the incoming students' preferences in higher education. The first stage of processing the questionnaire results focused on the preparation of a data matrix; data were sorted and coded according to the type of variables (qualitative, quantitative). During this phase, the data were cleaned, and the quality was checked in order to uncover any extremes (eccentric) or deviating observations, which could significantly influence the results of analyses. There were no missing values because all questions were mandatory. The last step of the data matrix processing involved the transformation of the variables, which fulfil conditions of a certain statistical method. The process of calculation and interpretation of results used methods similar to Hair (2011).

Applicants and enrolled students were marking offered wishful utterances in welcome post-purchase type entry questionnaire. Wishful utterances are projecting so bright outcomes of study that allow distinguishing students with over-expectations who usually hype and drop-off. It means that some of wishful utterances must not be selected as they are above the curve of normal distribution. Consistent attitudes of groups below curve of normal distribution (Roggers, 1983; Bass, 1969) were provoking intentions (Astington, 1993), stated choice (Fujii and Gärling, 2003) and perceived sufficiency of attributes. These attributes completed the listing of wishful utterances. The three entries into research framework fit with U-shape curve of Attribution Model of Online Advertising (Schulz and Dellnitz, 2017), which is used for reward distribution between participants of sales funnel, who are acquiring prospects and retaining clients. Pivotal utterances from inner and outer attitudes towards excellence were selected.
The qualitative data were processed using quantitative content analysis. The analysis used utilizes aspects of the text that are not apparent at first sight in a given amount of information. The procedure of the realized quantitative content analysis reflected the steps according to Disman (2002) with partial modifications according to the context of the research. First, there were defined statistically surveyed elements - synonyms, i.e. words, phrases or other parts of the text with similar meaning classified into categories and defined units to be analysed. Those units for analysis became particular terms, repeatedly mentioned by respondents. Terms were observed both as a whole (in certain context), but the attention was focused also on their particular components (words), phrases. For the creation of the qualification system, nominal qualification was created observing the frequency of the occurrences of the particular units in each category. The number of the occurrences of subcategories for each category was recorded.

The processing of the results was based on the analysis of the data focused on investigating important properties and the typical features of the statistical file. The statistical evaluation of the data undertaken firstly by a one-dimensional analysis based on the frequency distribution, the calculation of point and interval estimates and the testing of hypotheses about the frequency of the categories of individual variable values. Secondly, a two-dimensional analysis was used based on an investigation of the dependence of two selected variables. The goal of the comprehensive analysis of several variables was to uncover relations between data structures and to find an interpretation for these structures. Concretely, $F$-test and $t$-test were used.

Grouping of respondents was adapted for processing according to answers about future. Indices converting resignation to retention extracted from database provided answers in entrance survey. Four multiple-choice questions focused on retention:

- What do you expect from studies?

- What a graduate should know?

- What is important for you during studies?

- Where do you expect yourself to be after you finish studies?

Utterances oriented on output, process, input, and utility were offered to respondents (see Appendix). Offered utterances have reflected previous data collecting and processing experience of university staff according to incidence of marked utterances of retained clients. All respondents were allowed to mark more utterances, which seem to them either valid or synonymous. Therefore, less marked synonymous utterances could demonstrate ability of respondent to distinguish between them. Answers were coded 1 or 2 according to proximity with recent situation or 3 or 4 with proximity with competitiveness after graduation.

Option "other, describe, please" was marked by 31 of 535 student respondents. Written comments were received only from 14 of 31 . Therefore, written notes were not further studied. Used figures and data were processed and generated in IBM SPSS. 


\section{RESULTS}

Results presented below with the data from respondents (university applicants) were evaluated based on qualitative

content analysis and then assigned to one of the four groups according graphical appearance on answers of four questions (Table 1).

\begin{tabular}{|c|c|c|c|c|c|c|c|c|c|c|c|c|c|c|c|c|c|c|c|}
\hline \multicolumn{4}{|c|}{ Proactive } & \multicolumn{4}{|c|}{ Reactive } & \multicolumn{4}{|c|}{ Lazy } & \multicolumn{4}{|c|}{ Institutional } & \multicolumn{4}{|c|}{ Normal } \\
\hline & & & & & & & & & & & & & & & & & +1 & & \\
\hline & & & & & & & & & & & & & & & & & +1 & & \\
\hline & & & & & & & & & & & & & & & & & +2 & & \\
\hline & & & & & & & & & & & & & & & & & +3 & & \\
\hline & & & & & & +3 & & & & +2 & & & & & & & +0 & & \\
\hline & +0 & & & & & +2 & & & & +3 & +1 & & & & & +2 & +4 & +2 & \\
\hline & +4 & & & & & +3 & & & & +4 & +1 & & & & & +3 & +3 & +4 & +1 \\
\hline & +1 & & & & & +4 & +1 & +2 & & +2 & +1 & & & & & +2 & +2 & +3 & +1 \\
\hline+2 & +3 & & & & & +2 & +1 & +4 & & +3 & +1 & & & & & +3 & +1 & +3 & +1 \\
\hline+3 & +2 & +4 & +4 & +4 & +4 & +4 & +1 & +4 & +4 & +4 & +4 & +4 & +4 & +4 & +1 & +1 & +4 & +2 & +1 \\
\hline
\end{tabular}

Table 1: Graphical assignment of respondent to group - coded (Source: Own processing)

Respondents were assigned to group according to specifics of attitude they have recorded. Probability Distribution Function could not be used, except of normal group of respondents $(N=353)$. Therefore, answers of remaining four groups: proactive $(N=22)$, reactive $(N=42)$, lazy $(N=91)$, and institutional $(N=49)$ were processed according to normality biasing features. Sums of all answers for each of 4 code levels (CL) were tested on complementary accumulation or probabilistic effect. Small groups were merged to test CDF effect by PDF statistics oppose to normal group where PDF was present (Table 1). All four questions with all offered wishful utterances are in appendix. Selection from offered utterances are shown in columns with number of CL. CL4 means "all above", CL0 means the most wishful utterance like "manage a team". The most wishful utterance CL0 was not selected by any of five respondents in columns. Graphical example of number of answers of four questions shows differences between categories of respondents, which are described in heading row.

Resignation was found in tail of normal distribution containing Proactive respondents and Reactive respondents due to significant correlations with Normal respondents $(r=0.863$; $p<0.001$ ). On the other hand, there is no correlation between Normal and Institutional and Lazy respondents in oppose tail of normal distribution $(r=0.052 ; p=0.861)$. Significant differences of pairs show that each group behaves consistently except of groups in tails of normal distribution. The only retaining group in tails of normal distribution are Lazy and Institutional respondents. Those agree with all suggestions. Therefore, promotion of intelligent Lazy students retains other students according to our results.

Exact answers of the four identified groups are included in the attached questionnaire.

The examination of data has revealed different incidence of used synonyms in predefined answers on questions gradually concretising image of future career of respondent. Decreasing incidence of synonyms was typical for proactive respondents. Increasing incidence of synonyms was typical for reactive respondents. No synonyms used were typical for institutional respondents, who have chosen mostly answered "all above". No synonyms on second question with the most answers have differentiated group of lazy intelligent respondents. Finally, number of marked synonyms of normal group of respondents had normal distribution. Respondents were assigned to one of the four groups according to graphical appearance of answers on each of four questions, see Table 2. Mean, standard deviation and standard error mean of answers of respondents in tails of normal distribution are low oppose to Normal respondents in the centre of normal distribution. It explains why cumulative and complementary distribution function were searched in tails of normal distribution oppose to probabilistic function in centre of normal distribution. All pairs had 14 code levels.

For our calculations, 'synonym', considered if two or more answers appear on motivating question about long and inconsiderable future. Number of synonyms marked by respondents of different groups vary by $50 \%$ (Table 3 ). Code levels of variables in first column are specified in appendix and methodology. Percentage is calculated from occurrence of marked utterance and total number of respondents of each group. Percentages above 100 show that there were more utterances with the same code. Proactive respondents have selected predominantly competitive and developmental utterances. Normal and Lazy respondents have marked benefits the most often. High percentage of the lowest level of development by all groups of participants shows either low self-confidence or difficulty to imagine own potential.

The processing of such inconsistent data with conflicting attitudes as PDF would lead to recommendation of care for each student of group during their course of study and education individually. On the other hand, used CDF processing allows the improvement of both time and robustness for retention of possibly resigning participants (Table 4). Correlation and its significance were processed for 14 code levels of each pair of groups of respondents. Based on results of Table 4, it is possible to evaluate hypotheses stated in the theoretical part. H1a: Conformance of proactive and reactive respondents is confirmed by strong $(r=0.863)$ and significant $(p<0.001)$ correlation oppose to H1b, where weak and insignificant correlation of association of lazy intelligent and institutional respondents $(r=0.052 ; p=0.861)$. Therefore, there is almost no difference between fast start of proactive respondents if complemented by output focused on reactive respondents $(r=0.676 ; p=0.008)$ and normal respondents who need to wait for full understanding to external impulses. Readiness to wait for approaching external impulses is retaining students from resignation. 


\begin{tabular}{|c|c|c|c|c|}
\hline & & Mean & Std. Deviation & Std. Error Mean \\
\hline \multirow{2}{*}{ Pair 1} & Proactive_reactive & 30.785 & 32.555 & 8.701 \\
\hline & Normal PDF & 301.357 & 203.360 & 54.350 \\
\hline \multirow{2}{*}{ Pair 2} & Institutional_lazy & 47.642 & 49.147 & 13.135 \\
\hline & Normal PDF & 301.357 & 203.360 & 54.350 \\
\hline \multirow{2}{*}{ Pair 3} & CDF total & 78.428 & 63.604 & 16.998 \\
\hline & Normal_PDF & 301.357 & 203.360 & 54.350 \\
\hline \multirow{2}{*}{ Pair 4} & Proactive_reactive & 30.787 & 32.555 & 8.701 \\
\hline & Institutional_lazy & 47.642 & 49.147 & 13.135 \\
\hline \multirow{2}{*}{ Pair 5} & Proactive & 9.857 & 8.291 & 2.215 \\
\hline & Reactive & 20.929 & 26.371 & 7.048 \\
\hline \multirow{2}{*}{ Pair 6} & Lazy_intelligent & 39.357 & 37.497 & 10.021 \\
\hline & Institutional & 8.285 & 16.335 & 4.365 \\
\hline \multirow{2}{*}{ Pair 7} & Reactive & 20.928 & 26.371 & 7.048 \\
\hline & Lazy_intelligent & 39.357 & 37.497 & 10.021 \\
\hline \multirow{2}{*}{ Pair 8} & Institutional & 8.285 & 16.335 & 4.365 \\
\hline & Normal PDF & 301.357 & 203.360 & 54.350 \\
\hline \multirow{2}{*}{ Pair 9} & Institutional & 8.285 & 16.335 & 4.365 \\
\hline & Proactive & 9.857 & 8.291 & 2.215 \\
\hline \multirow{2}{*}{ Pair 10} & Institutional & 8.285 & 16.335 & 4.365 \\
\hline & Reactive & 20.928 & 26.371 & 7.048 \\
\hline \multirow{2}{*}{ Pair 11} & Lazy_intelligent & 39.357 & 37.497 & 10.021 \\
\hline & Proactive & 9.857 & 8.291 & 2.215 \\
\hline \multirow{2}{*}{ Pair 12} & Lazy_intelligent & 39.357 & 37.497 & 10.021 \\
\hline & Reactive & 20.928 & 26.371 & 7.048 \\
\hline
\end{tabular}

Table 2: Sorted data pairs for $t$-test (Source: Own processing)

\begin{tabular}{lcccccc}
\hline BAHAVIOUR / VARIABLE & Proactive & Reactive & Lazy & Institutional & Normal \\
\hline Number of respondents & 22 & 42 & 91 & 49 & 353 \\
\hline Competitive 3 & 11 & 6 & 32 & 0 & 195 \\
\hline Competitive 2 & $50.0 \%$ & $14.3 \%$ & $35.2 \%$ & $0.0 \%$ & $55.2 \%$ \\
\hline Manipulated 4 & 18 & 10 & 52 & 7 & 281 \\
\hline & $81.8 \%$ & $23.8 \%$ & $57.1 \%$ & $14.3 \%$ & $79.6 \%$ \\
\hline Manipulated 3 & 11 & 11 & 0 & 0 & 341 \\
\hline & $31.8 \%$ & $26.2 \%$ & $0.0 \%$ & $0.0 \%$ & $96.6 \%$ \\
\hline Manipulated 2 & 8 & 7 & 1 & 2 & 278 \\
\hline & $36.4 \%$ & $16.7 \%$ & $1.1 \%$ & $4.1 \%$ & $78.8 \%$ \\
\hline Benefits 4 & 7 & 9 & 0 & 3 & 290 \\
\hline & $31.8 \%$ & $21.4 \%$ & $0.0 \%$ & $6.1 \%$ & $82.2 \%$ \\
\hline Benefits 3 & 1 & 13 & 102 & 4 & 411 \\
\hline & $4.5 \%$ & $31.0 \%$ & $112.1 \%$ & $8.2 \%$ & $116.4 \%$ \\
\hline Benefits 2 & 2 & 15 & 62 & 0 & 263 \\
\hline & $9.1 \%$ & $35.7 \%$ & $68.1 \%$ & $0.0 \%$ & $74.5 \%$ \\
\hline Development 4 & 3 & 19 & 67 & 3 & 303 \\
\hline & $13.6 \%$ & $45.2 \%$ & $73.6 \%$ & $6.1 \%$ & $85.8 \%$ \\
\hline Development 3 & 0 & 13 & 19 & 0 & 70 \\
\hline & $0.0 \%$ & $31.0 \%$ & $20.9 \%$ & $0.0 \%$ & $19.8 \%$ \\
\hline Development 1 & 1 & 2 & 6 & 2 & 21 \\
\hline & $4.5 \%$ & $4.8 \%$ & $6.6 \%$ & $4.1 \%$ & $5.9 \%$ \\
\hline & 20 & 41 & 89 & 44 & 337 \\
\hline & $90.9 \%$ & $97.6 \%$ & $97.8 \%$ & $89.8 \%$ & $95.5 \%$ \\
\hline
\end{tabular}

Table 3: PDF oppose to CDF interactions (Source: Own processing) 


\begin{tabular}{llc|c} 
& & Correlation & $p$-value \\
\hline Pair 1 & Pro_reaction \& Normal_PDF & .863 & .000 \\
\hline Pair 2 & Institution_lazy \& Normal_PDF & .052 & .861 \\
\hline Pair 3 & CDF total \& Normal_PDF & .482 & .081 \\
\hline Pair 4 & Pro_reaction \& Institution_lazy & .178 & .542 \\
\hline Pair 5 & Proactive \& Reactive & .676 & .008 \\
\hline Pair 6 & Lazy_intelligent \& Institutional & .606 & .022 \\
\hline Pair 7 & Reactive \& Lazy_intelligent & .042 & .887 \\
\hline Pair 8 & Institutional \& Normální_PDF & .098 & .739 \\
\hline Pair 9 & Institutional \& Proactive & .583 & .029 \\
\hline Pair 10 & Institutional \& Reactive & .315 & .273 \\
\hline Pair 11 & Lazy_intelig \& Proaktive & .094 & .749 \\
\hline Pair 12 & Lazy_intelig \& Reactive & .042 & .887 \\
\hline
\end{tabular}

Table 4: Retention supporting correlations (Source: Own processing)

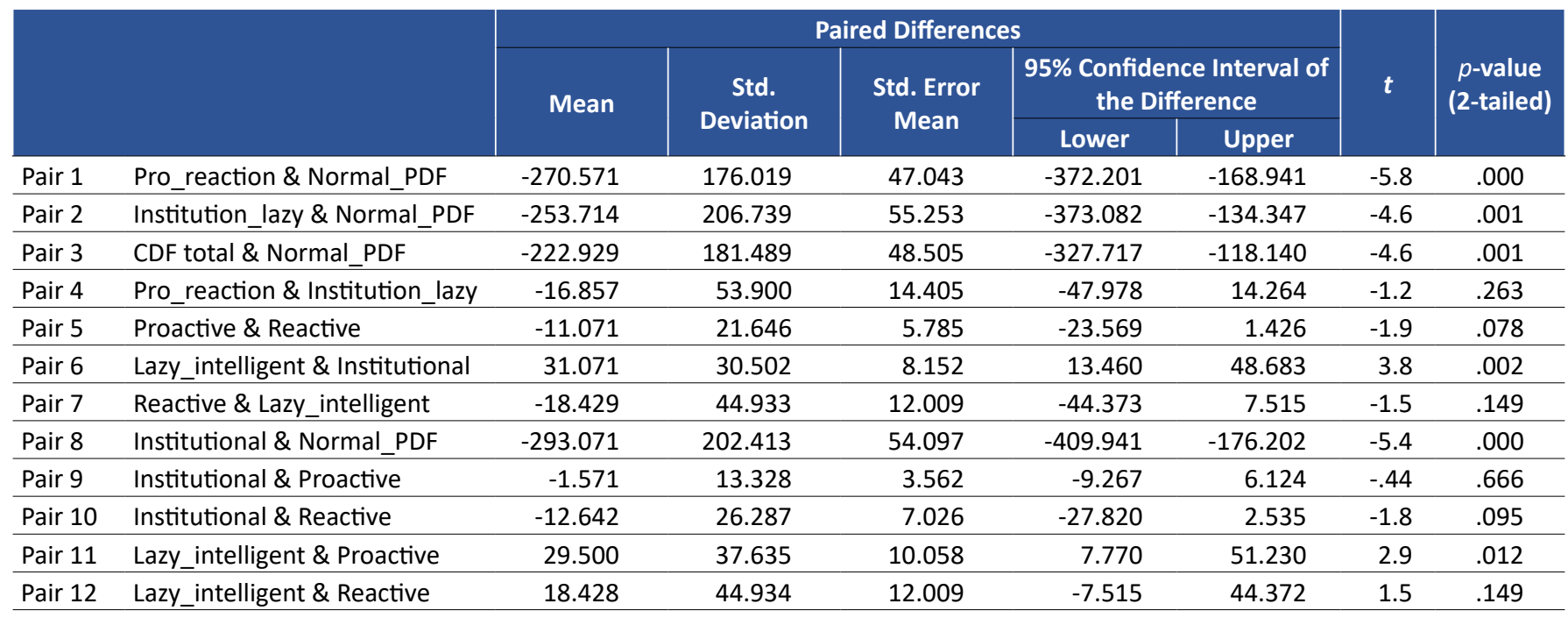

Table 5: Resignation supporting differences (Source: Own processing)

H1: Conversion of resignation to retention by association of proactive, reactive and normal respondents (Pair 1, Table 5) is the best of all other combinations.

Pair 3 CDF total \& Normal_PDF $(r=0.482)$ do not reliably deny neither confirm $\mathrm{H} 0$ that probability distribution function by trial and error marking synonyms in answers $(p=0.081)$. Normal PDF respondents are weak to compensate errors from adversary trials between innovative pro reactive and lazy institutional respondents oppose to tails of normal distribution.

H1a: Impatience of lazy/intelligent respondents has neither positive nor negative impact on resignation and retention, hypothesis rejected. Intelligent laziness has shown to be ideal to accompany institutionalists in institutions (Pair 5, $r=0.676 ; p=0.008$ ) but not in innovative university. Therefore, impatience of lazy intelligent respondents isn't confirmed as he or she is intelligent enough to be lazy instead of waiting for call of institution.

$\mathrm{H} 1 \mathrm{~b}$ : Institutional respondents are making conversion of resignation to retention unmanageable. Also, this hypothesis was not rejected by readiness to wait for institutional approval off-setting approach to external impulses. Therefore, promotion of image of institution by waiting for call to action by institutionalists $(t=-5.417$; $p<0.001)$ is pushing other students to resign from image of manageability of future career (Table 5). All values of all pairs had $d f 13$.

\section{DISCUSSION}

Results of the analysis show that synonyms in questionnaires are more useful for real time management than validated questions on emotions, attention, attitudes or logic which were used by Lutz, MacKenzie and Belch (1983), Muehling (1987), MacKenzie and Lutz (1989), and Mehta (2000). Still, this comparison is needed especially for synonyms in full text and discussions about future. Yu, et al (2016) iterates synonyms in vector space during discriminative training and measure the progress of the cognition of ambiguous cases. Ambiguous career of student and graduate from point of view of entry questionnaire is the example of such case, which should be monitored during training/ education. Dylman and Barry (2018) have measured performance differences of cognitive training according to expectations of receiver. Similarly, respondents in this article could mark more synonyms according to expected agreement with question to demonstrate their interest or 
promise to behave during studies at chosen university. Less often marked synonyms have demonstrated ability of respondent to distinguish between similar answers.

Hong et al (2016) stress flow experience, cognitive anxiety and learning progress to cognitive failure. They derived conclusion that negative correlation $(r=-0.53 ; p=0.001)$ between cognitive error during flow experience of habitual evaluation is blocking obtained information. Therefore, respondents' fear of rejection during entry questionnaire or test can be close to fear of error $(r=0.41 ; p=0.001)$, which can be compensated by more marked synonyms. Nevertheless, correlation $(r=0.863)$ between Proactive, Reactive and Normal respondents found in this article is much higher and more significant $(p=0.000)$. This confirms implacable attitude between Institutional and Lazy inside of PDF towards CDF respondents, which Waring (2019) assigns to Alt-Rights.

Chang (2017) has confirmed that consumers behave accidentally if no pressure of situation is perceived in tails of CDF. This absenting pressure in tails of normal distribution observation could also decrease the number of resigned and increase the number of retained students on CDF students should decrease if separated from PDF students. Moreover, the origin of different behaviour under or without stress needs to be further analysed according to new observations of epigenetics, which have found that restriction prevents associative learning deficits but not changes in brain protein-adduct formation during ageing (Tolfsten et al., 2011). In addition, there is a need for further generalisation of implacable attitudes into personnel agenda.

\section{CONCLUSIONS}

The results of this study show that students behave differently. By assigning students to their respective groups early in their studies, it can provide a more descriptive understanding of how to deal with these students to affect retention outcomes. This study used graphical qualitative method whether respondent belongs to Proactive, Reactive, Lazy, Institutional or Normal group, as we saw each group behaved differently impacting matriculation. Their expectations should be addressed by university staff and serve as an advisory according to the preferred attitudes to their identified group. This identification and communication with the differentiated groups of students leads to increased retention since it is possible to address problematic students in the beginning.

The four hypotheses identified in this study have shown synergy of respondents behaving according to Probabilistic Distribution Function and proactive and reactive respondents behaving according to Complementary Distribution Function. They can process synonyms allowing projection of innovative career but not institutional one. Therefore, heterogeneous groups of students should not meet and communicate otherwise objective of retention will not be reached. When groups are separated then both resignation decrease, and retention occurs spontaneously. Proactive with reactive students invite normal students and lazy intellectual with institutional students will follow.

Description of the four groups of students for better understanding of the results with the most important characteristics of the groups are provided here with special attention to the tendency of resignation and special treatments needed for retention. Resignation was found in tail of normal distribution containing Proactive students and Reactive students due to significant correlations with Normal respondents than correlations between Normal students and Institutional and Lazy respondents in the oppose tail of normal distribution. Significant differences of pairs show that each group behaves consistently except of groups in tails of normal distribution. The only retaining group in tails of normal distribution are Lazy and Institutional students which agree with all suggestions. Therefore, promotion of Lazy intelligent students would retain them according to our results.

Results of two-step cluster analysis of synonyms are shedding more light into analysis of groups when describing laziness by clusters specified by factor „voluntary attendance“ and „self-management" are the extreme of the most important output predictors and by factors of ,abilities“ and „methods“ at oppose ends of bipolar scale. Therefore, promotion of laziness with these four clustering factors will be fully understood and followed.

The school management may identify to which group the student belongs if the questions with predefined answers will be filled by enrolled students. Promotion on impact of methods and abilities on saving time and good results of study will pre-empt his/her drop off.

The practical measures, which should be made by the schools should promote interviews with recipes of Lazy intelligent students on their experience with retaining main and peripheral benefits $t$.

The topic of this article is currently highly relevant for all higher education institutions from the perspective of student retention and, last but not least, for the reason of evaluating the global quality level of education management. The article also reflects the progress in insisting on the quality of the higher education system of recruitment influenced by systematic analyses, evaluation and the strategic management of particular college or university. The article provides evidence of how early stratification of students based on their preferences can yield a better understanding of these students and ultimately impacting completion rates. The limit of this article is its narrow focus on a case university in the Czech Republic, but the results as a case study with outcomes can help other colleges and universities to improve identification of progressive applicants and new students and also those, who need instant help to retain them. Automatic data evaluation system can help to proceed students' answers in entry questionnaire and select those, who need further consultations and advisory. 
Agbola, F. W. and Cheng, C. (2017) 'Student's local top-up higher education choices', Studies in Continuing Education, Vol. 39, No. 3, pp. 333-356. https://doi.org/10.1080/0158037x.2017.1336994

Aghakhani, H. and Main, K. J. (2019) 'Can two negatives make a positive? Social exclusion prevents carryover effects from deceptive advertising', Journal of Retailing and Consumer Services, Vol. 47, pp. 206-214. https://doi.org/10.1016/j. jretconser.2018.11.021

AMA (2013) Marketing definitions, [Online], Accessed 19 April 2019. Available at: https://www.ama.org/the-definition-of-marketing/ [19 Apr 2019].

Aregbeyen, O. (2010) 'Students perceptions of effective teaching and effective lecturer characteristics at the University of Ibadan, Nigeria', Pakistan Journal of Social Sciences, Vol. 7, No. 2, pp. 62-69. https://doi.org/10.3923/pjssci.2010.62.69

Asma, L. (2017) 'There is No Free Won't the Role Definitions Play', Journal of Consciousness Studies, Vol. 24, No. 5-6, pp. 8-23.

Astington, J. W. (1993) The developing child. The child's discovery of the mind. Cambridge, MA, US: Harvard University Press.

Bass, F. (1969) 'A new product growth model for consumer durables', Management Science, Vol. 15, No. 5, pp. 215-227. https://doi. org $/ 10.1287 / \mathrm{mnsc} .1040 .0264$

Barnett, E., Moyers, T. B., Sussman, S., Smith, C., Rohrbach L. A., Sun, P. and Spruijt-Metz, D. (2014) 'From counselor skill to decreased marijuana use: Does change talk matter?', Journal of Substance Abuse Treatment, Vol. 46, No. 4, pp. 498-505. https:// doi.org/10.1016/j.jsat.2013.11.004

Benford, R. D. and Snow, D. A. (2000) 'Framing processes and social movements: an overview and assessment', Annual Review of Sociology, Vol. 26, pp. 611-639. https://doi.org/10.1146/annurev. soc.26.1.611

Boronczyk, F. and Breuer, C. (2019) 'The company you keep: Brand image transfer in concurrent event sponsorship', Journal of Business Research, [In Press, Corrected Proof]. https://doi. org/10.1016/j.jbusres.2019.03.022

Chang, C. (2017) 'How salient pictures in magazine advertisements bias consumers' preference construction: A comparison with product pages in e-stores applying dual system model', Journal of Consumer Behaviour, Vol. 17, No. 2, pp. 123-140. https://doi. org/10.1002/cb.1696

Colicev, A., Kumar, A. and O'Connor, P. (2019) 'Modeling the relationship between firm and user generated content and the stages of the marketing funnel', International Journal of Research in Marketing, Vol. 36. No. 1, pp. 100-116. https://doi. org/10.1016/j.ijresmar.2018.09.005

Collins, T. W., Grineski, S. E., Shenberger, J. Shenberger, J., Morales, X., Morera, O. F. and Echegoyen, L. E. (2017) 'Undergraduate Research Participation Is Associated With Improved Student Outcomes at a Hispanic-Serving Institution', Journal of college student development, Vol. 58, No. 4, pp. 583-600. https://doi. org/10.1353/csd.2017.0044

Deveci, H. (2015) 'Value education through distance learning: Opinions of students who already completed value education', Turkish Online Journal of Distance Education, Vol. 16, No. 1, pp. 112-126. https://doi.org/10.17718/tojde.89079

Disman, M. (2002) Jak se vyrábí sociologická znalost. Praha: Karolinum.
Duong, M. Q., Wu, C. L. and Hoang, M. K. (2017) 'Student inequalities in Vietnamese higher education? Exploring how gender, socioeconomic status, and university experiences influence leadership efficacy', Innovations in Education and Teaching International, Vol. 56, No. 1, pp. 110-120. https://doi.org/10.1080/14703297.2017.1377098

Dylman, A. S. and Barry, C. (2018) 'When having two names facilitates lexical selection: Similar results in the picture-word task from translation distractors in bilinguals and synonym distractors in monolinguals', Cognition, Vol. 171, pp. 151-171. https://doi. org/10.1016/j.cognition.2017.09.014

Esparza, G. G., De-Luna, A., Zezzatti, A. O., Hernandez, A., Ponce, J., Álvarez, M. Cossio, E. and Nava, J. J. (2018) 'A sentiment analysis model to analyze students reviews of teacher performance using support vector machines', Distributed Computing and Artificial Intelligence, Vol. 620, pp. 157-164. https://doi.org/10.1007/978-3319-62410-5 19

Fenn, J. (2007) Understanding Gartner's Hype Cycles, Gartner Research ID: G00144727.

Fetterman, A. K., Curtis, S., Carre, J. and Sassenberg, K. (2019) 'On the willingness to admit wrongness: Validation of a new measure and an exploration of its correlates', Personality and Individual Differences, Vol. 138, pp. 193-202. https://doi.org/10.1016/j.paid.2018.10.002

Fischer, D. J. and Moyers, T. B. (2014) 'Is there an association between empathic speech and change talk in motivational interviewing?', Alcoholism Treatment Quarterly, Vol. 32, No. 1, pp. 3-18. https:// doi.org/10.1080/07347324.2014.856225

Fujii, S, Gärling, T, (2003) 'Development of script-based travel mode choice after forced change', Transportation Research Part F: Traffic Psychology and Behaviour, Vol. 6, No. 2, pp. 117-124. https://doi. org/10.1016/S1369-8478(03)00019-6

Fürstenberg, S., Schick, K., Deppermann, J., Prediger, S., Berberat, P. O., Kadmon, M. and Harendza, S. (2017) 'Competencies for first year residents - Physicians' views from medical schools with different undergraduate curricula', BMC Medical Education, Vol. 17, No. 1, pp. 154. https://doi.org/10.1186/s12909-017-0998-9

Graham, J., Haidt, J. and Nosek, B. A. (2009) 'Liberals and conservatives rely on different sets of moral foundations', Journal of Personality and Social Psychology, Vol. 96, No. 5, pp. 1029-1046. https://doi. org/10.1037/a0015141

Guerin, C., Jayatilaka, A., Ranasinghe, D., McCulloch A. and Calder, P. (2017) 'Research degrees in Information and Communication Technology (ICT): Why so few doctoral students?', Journal of Further and Higher Education, Vol. 41, No. 5, pp. 625-641. https:// doi.org/10.1080/0309877X.2016.1159290

Hair J. F. (2011) 'Multivariate Data Analysis: An Overview', in Lovric M. (ed.) International Encyclopedia of Statistical Science, Berlin, Heidelberg: Springer. https://doi.org/10.1007/978-3-642-04898-2

Hong, J. C., Tai, K. H., Hwang, M. Y. and Kuo, Y. C. (2016) 'Internet cognitive failure affects learning progress as mediated by cognitive anxiety and flow while playing a Chinese antonym synonym game with interacting verbaleanalytical and motor-control', Computers \& Education, Vol. 100, pp. 32-44. https://doi.org/10.1016/j. compedu.2016.04.009

Kahneman, D. (2012) Thinking, fast and slow, London: Penguin Books.

Kember, D., Hong, C., Yau, V. W. K. and Ho, S. A. (2017) 'Mechanisms for promoting the development of cognitive, social and affective graduate attributes', Higher Education, Vol. 74, No. 5, pp. 799-814. https://doi.org/10.1007/s10734-016-0077-x 
Kim, M. K., Kim, S. M., Khera, O. and Getman, J. (2014) 'The experience of three flipped classrooms in an urban university: an exploration of design principles', Internet and Higher Education, Vol. 22, pp. 37-50. https://doi.org/10.1016/j.iheduc.2014.04.003

Kotler, P. (1991) Marketing Management, Englewood Cliffs, NJ: PrenticeHall International Editions.

Lee, Y., Ho, F. N. and Wu, M. (2018) 'How do form and functional newness affect adoption preference? the moderating role of consumer need for uniqueness', The Journal of Consumer Marketing, Vol. 35, No. 1, pp. 79-90. http://doi.org/10.1108/JCM-10-2015-1578

Libet, B. (1985) 'Unconscious cerebral initiative and the role of conscious will in voluntary action', Behavioral and Brain Sciences, Vol. 8, No. 4, pp. 529-539. https://doi.org/10.1017/s0140525x00044903

Liu, J., Liao, X., Huang, W. and Liao, X. (2019) 'Market segmentation: A multiple criteria approach combining preference analysis and segmentation decision', Omega, Vol. 83, pp. 1-13. https://doi. org/10.1016/j.omega.2018.01.008

Lloyd-Smith, P. and Adamowicz, W. (2018) 'Can stated measures of willingness-to-accept be valid? Evidence from laboratory experiments', Journal of Environmental Economics and Management, Vol. 91, pp. 133-149. https://doi.org/10.1016/j.jeem.2018.07.003

Lutz, R. J. MacKenzie, S. B. and Belch, G. E. (1983) 'Attitude toward the ad as a mediator of advertising effectiveness: Determinants and consequences', Advances in consumer research, Vol. 10, No. 1, pp. $532-539$.

Luu, N., Ngo, L. V. and Cadeaux, J. (2018) 'Value synergy and value asymmetry in relationship marketing programs', Industrial Marketing Management, Vol. 68, pp. 165-176. https://doi.org/10.1016/j. indmarman.2017.10.011

MacKenzie, S. B. and Lutz, R. J. (1989) 'An Empirical Examination of the Structural Antecedents of Attitude Toward the Ad in an Advertising Pretesting Context', Journal of Marketing, Vol. 53, No. 2, pp. 48-65. https://doi.org/10.1177/002224298905300204

Magill, M., Apodaca, T. R., Borsari, B., Gaume, J., Hoadley, A., Gordon, R. E. F., Tonigan, J. S. and Moyers, T. (2018) 'A meta-analysis of motivational interviewing processes: Technical, relational, and conditional process models of change', Journal of Consulting and Clinical Psychology, Vol. 86, No. 2, pp. 140-157. https://doi. org/10.1037/ccp0000250

Magill, M., Apodaca, T. R., Karno, M., Gaume, J., Durst, A., Walthers, J., Stout, R. L. and DiClemente, C. (2016) 'Reliability and validity of an observational measure of client decisionmaking: The client language assessment - Proximal/distal (CLA-PD)', Journal of Substance Abuse Treatment, Vol. 63, pp. 10-17. https://doi.org/10.1016/j. jsat.2015.12.006

Maloney, C. (2010) The secret to accelerating diffusion of innovation: the $16 \%$ rule explained, [online], Available: https://innovateordie.com. au/2010/05/10/the-secret-to-accelerating-diffusion-of-innovation-the16-rule-explained/ [3 March 2020].

Mehta, A. (2000) 'Advertising Attitudes and Advertising Effectiveness', Journal of Advertising Research, Vol. 40, No. 3, pp. 67-72. https://doi. org/10.2501/jar-40-3-67-72

Menon, M. E., Markadijs, E., Theodoropoulos, N. and Socratous, M. (2017) 'Influences on the intention to enter higher education: the importance of expected returns', Journal of Further and Higher Education, Vol. 41, No. 6, pp. 831-843. https://doi.org/10.1080/0309877x.2016.1188897

Muehling, D. D. (1987) 'An Investigation Of Factors Underlying AttitudeToward-Advertising-In-General', Journal of Advertising, Vol. 16, No. 1, pp. 32-40. https://doi.org/10.1080/00913367.1987.10673058
Pezoa-Fuentes, C. and Vidal-Suñé, A. (2017) 'Cluster perpetuation: Maintenance of competitive advantages over time. The case of Chile's large north', Resources Policy, Vol. 54, pp. 176-188. https:// doi.org/10.1016/j.resourpol.2017.10.001

Reifkind, B. (2018) Ghosting has hit the office, [Online], Available: https:// www.linkedin.com/feed/news/ghosting-has-hit-the-office-4760330/ [20 Dec 2018].

Roggers, E. M. (1983) Diffusion of Innovations, London: The Free Press.

Sayer, A. (2011) Why things matter to people: Social science, values and ethical life, Cambridge: Cambridge University Press.

Schulz, C. and Dellnitz, A. (2017) 'Attribution Model of Online Advertising', In Yang, K. (ed.) Multi-Platform Advertising Strategies in the Global Marketplace. Hershey, PA: IGI Global. https://doi. org/10.4018/978-1-5225-3114-2.ch009

Schumpeter, J. A. (1926) Theorie der wirtschaftlichen Entwicklung, München and Leipzig: Duncker \& Humblot.

Staiculescu, C. and Dobrea, R. C. (2017) 'Impact of the career counselling services on employability', European Proceedings of Social and Behavioural Sciences, Vol. 23, pp. 938-945.

Stevens, A. and Zampini, G. F. (2018) 'Drug policy constellations: A Habermasian approach for understanding English drug policy', International Journal of Drug Policy, Vol. 57, pp. 61-71. https://doi. org/10.1016/j.drugpo.2018.03.030

Taleb, N. N. (2013) Antifragile, London: Penguin Books.

Thatcher, I., Alao, H., Brown, C., I. and Choudhary, S. (2016) 'Enriching the values of micro and small business research projects: co-creation service provision as perceived by academic, business and student', Studies in Higher Education, Vol. 41, No. 3, pp. 560-581. https://doi. org/10.1080/03075079.2014.942273

Tolfsten, C. C., Baker, N., Kreibich, C. and Amdam, G. V. (2011) 'Flight restriction prevents associative learning deficits but not changes in brain protein-adduct formation during honeybee ageing', Journal of Experimental Biology, Vol. 214, No. 8, pp. 1322-1332. https://doi. org/10.1016/10.1242/jeb.049155

Tversky, A. and Kahneman, D. (1983) 'Extensional versus intuitive reasoning: The conjunction fallacy in probability judgment', Psychological Review, Vol. 90, No. 4, pp. 293-315. https://doi. org/10.1037//0033-295x.90.4.293

Villarosa-Hurlocker, M. C., O’Sickey, A. J., Houck, J. M. and Moyers, T. B. (2019) 'Examining the influence of active ingredients of motivational interviewing on client change talk', Journal of Substance Abuse Treatment, Vol. 96, pp. 39-45. https://doi. org/10.1016/j.jsat.2018.10.001

Wang, Z., Busemeyer, J. R., Atmanspacher, H. and Pothos, E. (2013) 'The Potential of Using Quantum Theory to Build Models of Cognition', Topics in Cognitive Sciences, Vol. 5, No. 4, pp. 672-688. https://doi. org/10.1111/tops. 12043

Waring, A. (2019) 'The five pillars of occupational safety \& health in a context of authoritarian socio-political climates', Safety Science, Vol. 117, pp. 152-163. https://doi.org/10.1016/j.ssci.2019.04.008

Yu, L. C., Lee, L. H., Yeh, J. F., Shih, H. M. and Lai, Y. L. (2016) 'Nearsynonym substitution using a discriminative vector space model', Knowledge-Based Systems, Vol. 106, pp. 74-84. https://doi. org/10.1016/j.knosys.2016.05.025

Zhang, L., Cao, T. and Wang, Y. (2018) 'The mediation role of leadership styles in integrated project collaboration: An emotional intelligence perspective.' International Journal of Project Management, Vol. 36, No. 2, pp. 317-330. https://doi.org/10.1016/j.ijproman.2017.08.014 


\section{USED CODES OF ANSWERS TO RESEARCH FRAMEWORK}

Questions and answers (It was possible to mark more options per question) QUESTION ON COMPETITIVE VARIABLES 1 . What do you expect from studies?

\begin{tabular}{ll}
\hline a) deep knowledge in studied domain & 2 \\
\hline b) general overview & 1 \\
\hline c) critical thinking & 2 \\
\hline d) ability of independent analysis & 3 \\
\hline e) ability to find new information & 2 \\
\hline f) ability of information processing & 3 \\
\hline g) all above & 4 \\
\hline h) nothing from above & 0 \\
\hline i) other, describe, please & 2 \\
\hline QUESTION ON MANIPULATED VARIABLES 2. What an absolvent should know?
\end{tabular}

a) work independently 2

b) find own position at labour market or in job 3

c) work in team 4

$\begin{array}{ll}\text { d) manage team } & 0\end{array}$

e) manage self (time management, stress management and similar domains) 2

f) plan assessment for own development and reaching own objectives 3

g) decision making according to qualification 1

$\begin{array}{ll}\text { h) presenting skills } & 1\end{array}$

i) communicate in two languages at least 1

j) use analytical methods of studied program 4

$\begin{array}{ll}\text { k) derive consequences } & 1\end{array}$

l) extrapolate, assess plans for future period 4

m) manage own business unit 3

n) all above 4

o) nothing from above 0

p) other, describe, please 2

QUESTION ON BENEFITS NEEDED 3. What is important during studies for you?

\begin{tabular}{ll}
\hline a) accessibility of resource materials & 4 \\
\hline b) flexibility of examinations & 2 \\
\hline c) voluntarily attendance & 2 \\
\hline d) available individual consultations & 3 \\
\hline e) own study plan assessment & 4 \\
\hline f) expert knowledge and abilities of teachers & 2 \\
\hline g) practical implications & 3 \\
\hline h) all above & 4 \\
\hline i) nothing from above & 0 \\
\hline j) other, describe, please & 4
\end{tabular}

QUESTION ON EXPECTED DEVELOPMENT 4. Where do you see yourself after graduation?

\begin{tabular}{ll}
\hline a) career progress & 1 \\
\hline b) better post & 1 \\
\hline c) better post protected by title & 1 \\
\hline d) better remuneration & 1 \\
\hline e) better non-financial appreciation & 4 \\
\hline f) better life style & 1 \\
\hline g) all above & 1 \\
\hline h) nothing from above & 4 \\
\hline i) other, describe, please & 3 \\
\hline
\end{tabular}

Source: university data, codes added. 